\title{
Intimal Hyperplasia after Vascular Injury Is Inhibited by Antisense cdk 2 Kinase Oligonucleotides
}

\author{
Ryuichi Morishita, Gary H. Gibbons, Kristin E. Ellison, Masatoshi Nakajima, Heiko von der Leyen, \\ Lunan Zhang, Yasufumi Kaneda, ${ }^{*}$ Toshio Ogihara, ${ }^{\star}$ and Victor J. Dzau \\ Division of Cardiovascular Medicine, Falk Cardiovascular Research Center, Stanford University School of Medicine, Stanford, California \\ 94305; and *Institute for Cellular and Molecular Biology, and ${ }^{\ddagger}$ Department of Geriatric Medicine, Osaka University Medical School, \\ Osaka 565, Japan
}

\section{Abstract}

The cell cycle regulatory enzyme, cdk (cyclin-dependent kinase) $\mathbf{2}$ kinase, is activated in the rat carotid artery after balloon angioplasty injury, and may mediate smooth muscle proliferation. To test the hypothesis that inhibition of the expression of this key enzyme can inhibit intimal hyperplasia, we studied the effect of antisense phosphorothioate oligodeoxynucleotides (ODN) against cdk 2 kinase administered by intraluminal delivery using hemagglutinating virus of Japan (HVJ)-liposomemediated transfer. The specificity of antisense cdk 2 ODN was confirmed by the observation that mRNA level of cdk 2 kinase in injured vessels was markedly diminished by the antisense ODN treatment. At 2 wk after transfection, antisense cdk 2 ODN treatment (15 $\mu \mathrm{M})$ resulted in a significant inhibition $(60 \%)$ in neointima formation, compared with sense ODNtreated and untreated vessels. Since we have previously observed that cell division cycle 2 kinase mRNA was also activated after vascular injury, we administered the combination of antisense cdc 2 and cdk 2 ODN in this study. Antisense cdc 2 ODN alone (15 $\mu \mathrm{M})$ only reduced intimal formation by $40 \%$. Combined antisense treatment resulted in near complete inhibition of neointima formation. To understand the mechanism of the sustained effect of a single antisense ODN administration, we examined kinetics of ODN in the vessel wall. Using phosphorothioate FITC-labeled ODN, we transfected carotid artery using the HVJ-liposome method. Fluorescence localized immediately to the medial layer, and persisted up to $2 \mathrm{wk}$ after transfection. These results demonstrate that a single intraluminal administration of antisense ODN directed to cell cycle regulatory genes (e.g., cdk 2 kinase) using the HVJ method can result in a sustained inhibition of neointima formation after balloon angioplasty in rat carotid injury model. (J. Clin. Invest. 1994. 93:1458-1464.) Key words: gene therapy • cdk 2 kinase $\bullet$ hemagglutinating virus of Japan transfer method - restenosis • FITC-labeled ODN

\section{Introduction}

Neointimal hyperplasia after balloon injury results from vascular smooth muscle cell migration and proliferation (1-3). Many growth factors, including thrombin, fibroblast growth

Address correspondence to Dr. Victor J. Dzau, Falk Cardiovascular Research Center, Stanford University School of Medicine, 300 Pasteur Drive, Stanford, CA 94305-5246.

Received for publication 29 July 1993 and in revised form 19 October 1993.

J. Clin. Invest.

(c) The American Society for Clinical Investigation, Inc

0021-9738/94/04/1458/07 \$2.00

Volume 93, April 1994, 1458-1464 factor, and PDGF, mediate neointima formation by activating cell cycle progression (4-7). Since cyclin was first discovered, it has become clear that cell growth is dependent on the coordinated actions of cell cycle regulatory genes $(8,9)$. Recent reports that the transcription factor, E2F, forms a complex with cyclin A and cdk (cyclin-dependent kinase) 2 kinase reveal that activation and phosphorylation of these cell cycle regulatory genes are critical to the process of cell growth and proliferation (10-12). Previously, we observed an increased gene expression of cell division cycle (cdc) 2 kinase in injured rat carotid arteries (13). The enzyme cdk 2 kinase, cloned as a homologue of cdc 2 kinase (14), plays an important role in transition through the $G_{1 / s}$ phase, whereas cdc 2 kinase is important in the $G_{2 / M}$ phase. Recent progress in the study of cell cycle progression regulation has reinforced the pivotal importance of the $G_{1 / s}$ phase in the process of cell proliferation ( 15 , 16). Therefore, we hypothesize that cdk 2 kinase may play a critical role in neointima formation. Using antisense phosphorothioate oligodeoxynucleotides (ODN) ${ }^{1}$ against cdk 2 kinase, this study tests the hypothesis that inhibition of the expression of this key enzyme can inhibit neointimal hyperplasia after balloon injury of the rat carotid artery.

The antisense method is an innovative and attractive strategy to block the transcription or translation of specific genes. Modifications of the ODN backbone such as phosphorothioate have resulted in increased resistance to nucleases. Using the modified ODN, Simons et al. (17) have recently reported that antisense ODN directed against c-myb inhibited neointima formation when administrated at high doses $(200 \mu \mathrm{g} / \mathrm{vessel})$ via a periadventitial pluronic gel delivery system. However, this peri-adventitial delivery method is impractical for the purpose of preventing restenosis after percutaneous transluminal angioplasty. We have therefore developed an intraluminal antisense ODN delivery system as a more efficient therapeutic strategy. To increase efficiency of cellular uptake of ODN, we have developed a highly effective hemagglutinating virus of Japan (HVJ)-liposome method that enhances uptake of ODN packaged in liposomes coated with inactivated HVJ (18-23). HVJ promotes fusion of the liposome with vascular cells and delivers the ODN intracellularly (23). Using this molecular delivery system, this study shows that a single intraluminal administration of antisense cdk 2 kinase ODN resulted in sustained ODN stability within the vessel wall and prevented neointima formation after balloon injury in rat carotid artery model.

\section{Methods}

Synthesis of oligonucleotides and selection of sequence targets. The sequences of ODN against human cdk 2 kinase used in this study were:

1. Abbreviations used in this paper: cdc, cell division cycle; ODN, oligodeoxynucleotides; HVJ, hemagglutinating virus of Japan; RT, reverse transcription. 
antisense, 5'-GAA-GTT-CTC-CAT-GAA-GCG-3'; sense, 5'-CGCTTC-ATG-GAG-AAC-TTC-3' ( -6 to +12 of human sequence; these sequences are not different between mouse and human cdk 2 kinase). This antisense ODN specifically inhibits cdk 2 kinase protein synthesis and serum-stimulated growth in rat VSMC (our unpublished observation). We also synthesized sense and antisense cdc 2 kinase ODN (antisense, 5'-GTC-TTC-CAT-AGT-TAC-TCA-3'; sense, 5'-TGA-GTAACT-ATG-GAA-GAC-3'; -9 to +9 of mouse sequence) (24). Scrambled ODN (5'-CTT-CGT-CGG-TAC-CGT-CTT-C-3'), a 4-bp missense of the cdc 2 kinase antisense ODN (5'-GTCTGCCGTCGTTAGTCA-3'), and antisense thrombomodulin (5'-ACC-CAGAAA-GAA-AAT-CCC-3') were used as additional negative controls. Synthetic ODN were purified over a NAP 10 column (Pharmacia Fine Chemicals, Piscataway, NJ) and quantitated by spectrophotometry (25).

Preparation of HVJ-liposomes. Phosphatidylserine, phosphatidylcholine, and cholesterol were mixed in a weight ratio of 1:4:8:2 (1923). Dried lipid was hydrated in $200 \mu$ l of balanced salt solution (BSS: $137 \mathrm{mM} \mathrm{NaCl}, 5.4 \mathrm{mM} \mathrm{KCl}, 10 \mathrm{mM}$ Tris- $\mathrm{HCl}, \mathrm{pH}$ 7.6) containing sense or antisense ODN. The control group did not contain ODN ( 200 $\mu$ l BSS). Liposomes were prepared by shaking and sonication. Purified $\mathrm{HVJ}$ ( $Z$ strain ) was inactivated by UV irradiation $\left(110 \mathrm{erg} / \mathrm{mm}^{2}\right.$ per s) for $3 \mathrm{~min}$ just before use. The liposome suspension $(0.5 \mathrm{ml}$, containing $10 \mathrm{mg}$ of lipids) was mixed with $\mathrm{HVJ}$ ( 10,000 hemagglutinating units) in a total volume of $4 \mathrm{ml} \mathrm{BSS}$. The mixture was incubated at $4^{\circ} \mathrm{C}$ for 5 min and then for $30 \mathrm{~min}$ with gently shaking at $37^{\circ} \mathrm{C}$. Free $\mathrm{HVJ}$ was removed from the HVJ-liposomes by sucrose density gradient centrifugation. In this study, the preparation of HVJ complex was optimized to achieve the maximum effect of antisense ODN in VSMC (data not shown).

In vivo gene transfer. A 2 French Fogarty catheter was used to induce vascular injury in male Sprague-Dawley rats (400-500 g; Charles River Labs., Wilmington, MA) (13). These rats were anesthetized with ketamine, and the left common carotid artery was surgically exposed. A cannula was introduced into the common carotid via the external carotid artery. In vivo gene transfer was performed under the following condition: vascular injury of the common carotid was induced by the passage and inflation of a balloon catheter through an arteriotomy in the external carotid artery three times. The injured segment was transiently isolated by temporary ligatures. The HVJ-liposome complex, liposome complex without HVJ particles, or ODN alone was infused into the segment and incubated for $10 \mathrm{~min}$ at room temperature. After a 10-min incubation, the infusion cannula was removed. After the transfection, blood flow to the common carotid was restored by release of the ligatures, and the wound was then closed. No adverse neurological or vascular effects were observed in any animal undergoing this procedure.

Reverse transcription ( $R T)$-PCR. RNA was extracted from antisense or sense ODN ( $15 \mu \mathrm{M}$ cdk 2 kinase, wrapped in liposomes)treated injured vessels by RNAzol ( Tel-Test Inc., Friendswood, TX) at 1 and $14 \mathrm{~d}$ after transfection. Contralateral arteries in antisense ODNtransfected animals were also used as intact arteries. Levels of cdk 2 and beta-actin mRNAs were measured by RT-PCR (13). The cdk $25^{\prime}$ primer (nucleotides -6 to +12 of human sequence) was $5^{\prime}$-CGCTTCATGGAGAACTTC-3'; the 3' primer (nucleotides 340-357) was 5'ATGGCAGAAAGCTAGGCC-3'. The primers complementary to the rat beta-actin gene were 5'-TTGTAACCAACTGGGACGATATGG3'; the $3^{\prime}$ primer was 5'-GATCTTGATCTTCATGGTGCTAGG-3' (kindly donated by Clontech Laboratories Inc., Palo Alto, CA). Extreme care was taken to avoid contamination of tissue samples with trace amounts of experimental RNA. Aliquots of RNA derived from intact and injured vessels were amplified simultaneously by PCR ( 35 cycles) and compared with a negative control (primers without RNA). Amplification products were subjected to electrophoresis through $2 \%$ agarose gels stained with ethidium bromide.

In vivo transfection of antisense $O D N$. After balloon injury as described above, $200 \mu \mathrm{l}$ of $\mathrm{HVJ}$-liposomes complex containing either antisense cdk 2 kinase ODN, antisense cdc 2 kinase ODN, sense ODN to the above, 4-bp missense of the cdc 2 kinase antisense ODN, scram- bled ODN, or antisense thrombomodulin ODN (each at 3 or $15 \mu \mathrm{M}$ contained in liposome $=$ total of 4 or $20 \mu \mathrm{g}$ ODN/vessel, respectively) was incubated within the lumen for $10 \mathrm{~min}$. Direct ODN transfer without liposomes (cdk 2 ODN: $150 \mu \mathrm{M}=$ total of $200 \mu \mathrm{g} / \mathrm{vessel}$ ), and liposome-mediated transfers without the HVJ particle (cdk 2 ODN: 15 $\mu \mathrm{M}=$ total of $20 \mu \mathrm{g} /$ vessel) were also examined in injured carotid arteries. At 2 wk after transfection, rats were killed and vessels were perfusion fixed with $4 \%$ paraformaldehyde. Neointima size was quantitated by morphometry by individuals who were blinded to the identity of the samples. Intimal and medial areas were measured on a digitizing system (2200; Southern Micro Instruments, Atlanta, GA).

In vivo transfection of FITC-labeled ODN. FITC-labeled phosphorothioate ODN was kindly provided by Clontech Inc. (Palo Alto, CA). FITC was labeled on the $3^{\prime}$ and $5^{\prime}$ ends of the ODN (16 bp) using fluorescein-ON phosphoramidite. Animal surgery was performed as described above. Transfer of phosphorothioate ODN was performed under two protocols: $(a)$ HVJ complex with FITC-labeled phosphorothioate ODN $(3 \mu \mathrm{M})$ was incubated for $10 \mathrm{~min}$; $(b)$ ODN in liposomes without HVJ particles: liposome complex with ODN $(3 \mu \mathrm{M})$, but without HVJ particles, was incubated for $10 \mathrm{~min}$. The vessels were harvested at $10 \mathrm{~min}$, and 1, 4, 7, and $14 \mathrm{~d}$ after transfection and perfusion fixed with $4 \%$ paraformaldehyde. Sections were examined by fluorescence microscopy, after staining in erichrome black $T$ solution. Elastic fibers stained dark red and are readily distinguishable from the specific FITC ODN by the treatment of erichrome black T solution (data not shown), consistent with the previous report (26).

Statistical analysis. All values are expressed as mean \pm SEM. Analysis of variance with subsequent Duncan's test was used to determine significant differences in multiple comparisons. $P<0.05$ was considered significant.

\section{Results}

$R T-P C R$ of $c d k 2$ kinase $m R N A$ expression in vivo. To investigate the role of cell cycle regulatory genes in neointima formation, we initially examined changes in mRNA expression of cdk 2 kinase in response to vascular injury. RNA from either the vessels transfected with antisense or sense cdk 2 ODN (15 $\mu \mathrm{M}$ ) was amplified by RT-PCR (Fig. 1). At $1 \mathrm{~d}$ after injury, RT-PCR of RNA from injured vessels transfected with sense ODN demonstrated a single band corresponding to cdk 2 kinase mRNA. The uninjured carotid vessel had undetectable levels of cdk 2 kinase mRNA. Administration of antisense cdk 2 ODN abolished the increased mRNA expression of cdk 2

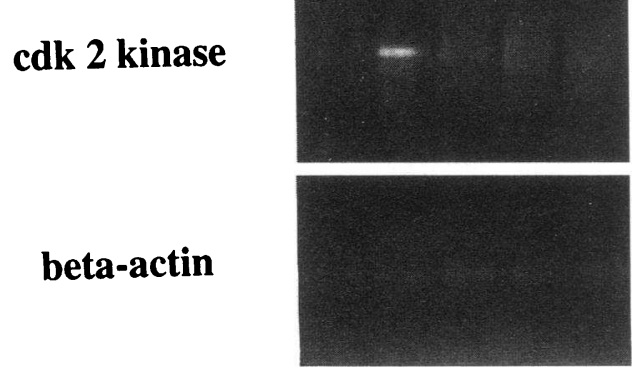

\section{$\begin{array}{lllll}1 & 2 & 3 & 4 & 5\end{array}$}

Figure 1. RT-PCR of cdk 2 kinase mRNA in vivo. (Lane 1) Intact uninjured carotid artery (contralateral vessel); (lane 2) injured vessel at $1 \mathrm{~d}$ after transfection of sense ODN; (lane 3) injured vessel at 1 $\mathrm{d}$ after transfection of antisense ODN; (lane 4) injured vessel at $14 \mathrm{~d}$ after transfection of sense ODN; (lane 5) injured vessel at $14 \mathrm{~d}$ after transfection of antisense ODN. 
kinase, but did not affect the level of beta-actin mRNA. At $14 \mathrm{~d}$ after injury, cdk 2 kinase mRNA was not detectable in either sense or antisense ODN-treated vessels. In contrast, constitutive mRNA expression of beta-actin remained unaffected.

Effect of antisense cdk 2 kinase ODN. We administered antisense cdk 2 kinase phosphorothioate ODN to injured rat carotid artery. As shown in Fig. 2, untreated and sense ODN ( 3 and $15 \mu \mathrm{M})$-transfected vessels exhibited neointimal formation at 2 wk after transfection. In contrast, a single administration of antisense cdk 2 kinase $\operatorname{ODN}(3 \mu \mathrm{M})$ resulted in a significant reduction in neointima formation ( $\sim 65 \%$ as compared with sense ODN-treated vessels). At high dose of $15 \mu \mathrm{M}$, antisense cdk 2 ODN appeared to result in a further inhibition of neointima formation, but this did not reach statistical significance (Fig. 2). ODN treatment did not alter the medial area (Fig. 2). The reduction in neointima formation was limited to transfected regions (neointimal/medial areas ratio: transfected region $=0.597 \pm 0.131$ vs. untransfected region $=1.156 \pm 0.079$; $P<0.01)$. To investigate the contribution of $\mathrm{HVJ}$ transfer to the effect of ODN in vivo, we compared the biological action of antisense cdk 2 ODN using the direct transfer, liposome-mediated transfer without the HVJ particle, and the HVJ-liposome method. Neither direct passive transfer at 10 -fold higher concentrations $(150 \mu \mathrm{M})$ nor liposome-mediated transfer without the HVJ particle ( $15 \mu \mathrm{M})$ had any inhibitory effect on the neointimal lesion (Fig. 3).

It is noteworthy that antisense cdk 2 kinase ODN did not completely suppress neointima formation. We have observed that cdc 2 kinase mRNA is also induced after vascular injury (13). Given the coordinated interaction of cdc 2 and cdk 2 kinase in the regulation of cell cycle progression, we postulated that concomitant inhibition of both factors would be the most effective therapeutic strategy. Indeed, the combination of antisense cdc 2 and cdk 2 kinase ODN showed further inhibition of neointima formation ( $85 \%$ ) as compared with either antisense cdc 2 or cdk 2 kinase ODN alone (Fig. 4). The administration of antisense cdc 2 kinase ODN alone only partially inhibited

E NEOINTIMAL AREAS MEDIAL AREAS

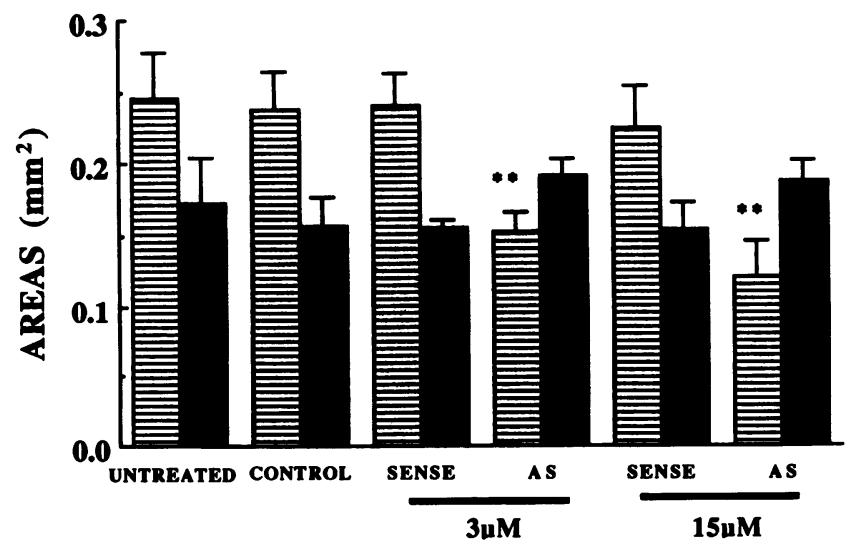

Figure 2. Effect of antisense and sense ODN of cdk 2 kinase on intimal and medial areas. (UNTREATED) Injured vessels without any treatment; (CONTROL) injured vessels treated with HVJ-liposomes without ODN; (SENSE) injured vessels treated with sense HVJODN; $(A S)$ injured vessels treated with antisense HVJ-ODN. ${ }^{* *} P$ $<0.01$ vs. sense. Each group contains five to eight animals.

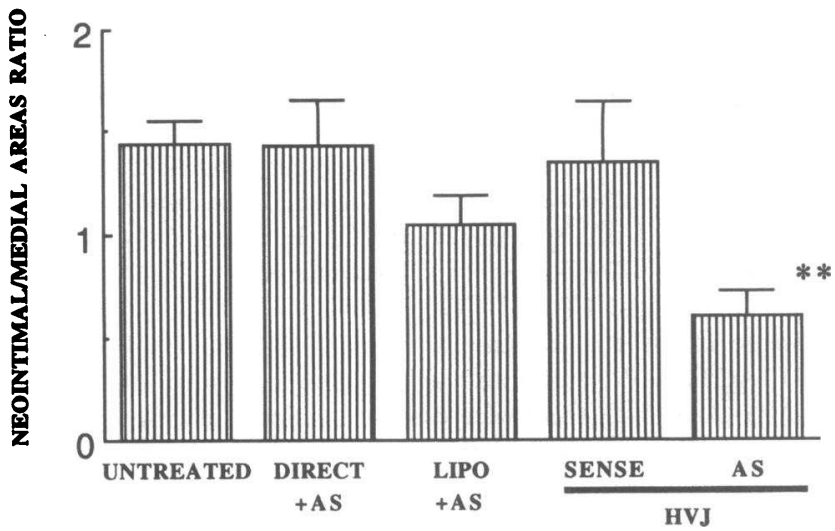

Figure 3. Comparison of transfer methods (direct transfer, liposomemediated transfer without $\mathrm{HVJ}$ particles, $\mathrm{HVJ}$-liposome method) on the neointimal/medial area ratio. (UNTREATED) Injured vessels without any treatment; $(D I R E C T+A S)$ injured vessels treated with antisense ODN $(150 \mu \mathrm{M}) ;(L I P O+A S)$ injured vessels treated with antisense ODN ( $15 \mu \mathrm{M})$ enwrapped in liposome without HVJ particles; $(H V J+S E N S E)$ injured vessels treated with sense HVJ-ODN $(15 \mu \mathrm{M}) ;(H V J+A S)$ injured vessels treated with antisense $\mathrm{HVJ}-$ ODN $(15 \mu \mathrm{M}) .{ }^{* *} P<0.01$ vs. other groups. Each group contains six to eight animals.

neointima formation. In contrast, treatment with scrambled ODN ( $15 \mu \mathrm{M})$ had no effect on neointima formation. Further evidence for the specificity of antisense cell cycle regulatory genes ODN was provided by the observations that treatment with a sense ODN to cdc 2 kinase did not affect neointimal formation (Fig. 4) and treatment with a 4-bp mismatch of the antisense to cdc 2 kinase ODN also had no effect (missense, $1.43 \pm 0.19$ vs. scrambled, $1.76 \pm 0.40 ; P>0.05)$. In addition, the treatment with antisense thrombomodulin ODN had no effect on neointima hyperplasia (antisense thrombomodulin, $1.551 \pm 0.099$ vs. untransfected lesions, $1.625 \pm 0.183 ; P>0.05)$.

Localization and kinetics of FITC-labeled phosphorothioate $O D N$. The sustained effect of a single intraluminal administration of antisense ODN led us to examine the fate and kinetics of transfected ODN using the HVJ-liposome method. Specifically, we hypothesized that the enhanced therapeutic efficiency of in vivo gene transfer with the HVJ-antisense ODN as compared with liposome-mediated transfer is due to enhanced transfer efficiency and ODN stability. We performed in vivo transfer of FITC-labeled ODN into injured carotid arteries using the HVJ-liposome method versus liposomes alone without the HVJ particle. Liposome-mediated transfer of FITC phosphorothioate ODN without HVJ particles into rat carotid arteries exhibited fluorescence in the medial layer at $10 \mathrm{~min}$ after transfection (Fig. $5 \mathrm{~A}$ ). However, this fluorescence disappeared by $4 \mathrm{~d}$ after transfection. In contrast, transfer of FITC phosphorothioate ODN by the HVJ method resulted in widespread distribution of fluorescence in medial vascular cells by $10 \mathrm{~min}$ after transfection. The fluorescence was localized primarily in cell nuclei (Fig. $5 \mathrm{~B}$ ), and persisted up to 2 wk after transfection. Untreated or $\mathrm{HVJ}$ complex without ODN-treated vessels revealed no specific fluorescence (except autofluorescence) in the elastic lamina (data not shown). Fluorescence resulting from FITC-labeled ODN was easily distinguished from the background autofluorescence. Intraluminal incubation of free FITC did not result in specific fluores- 


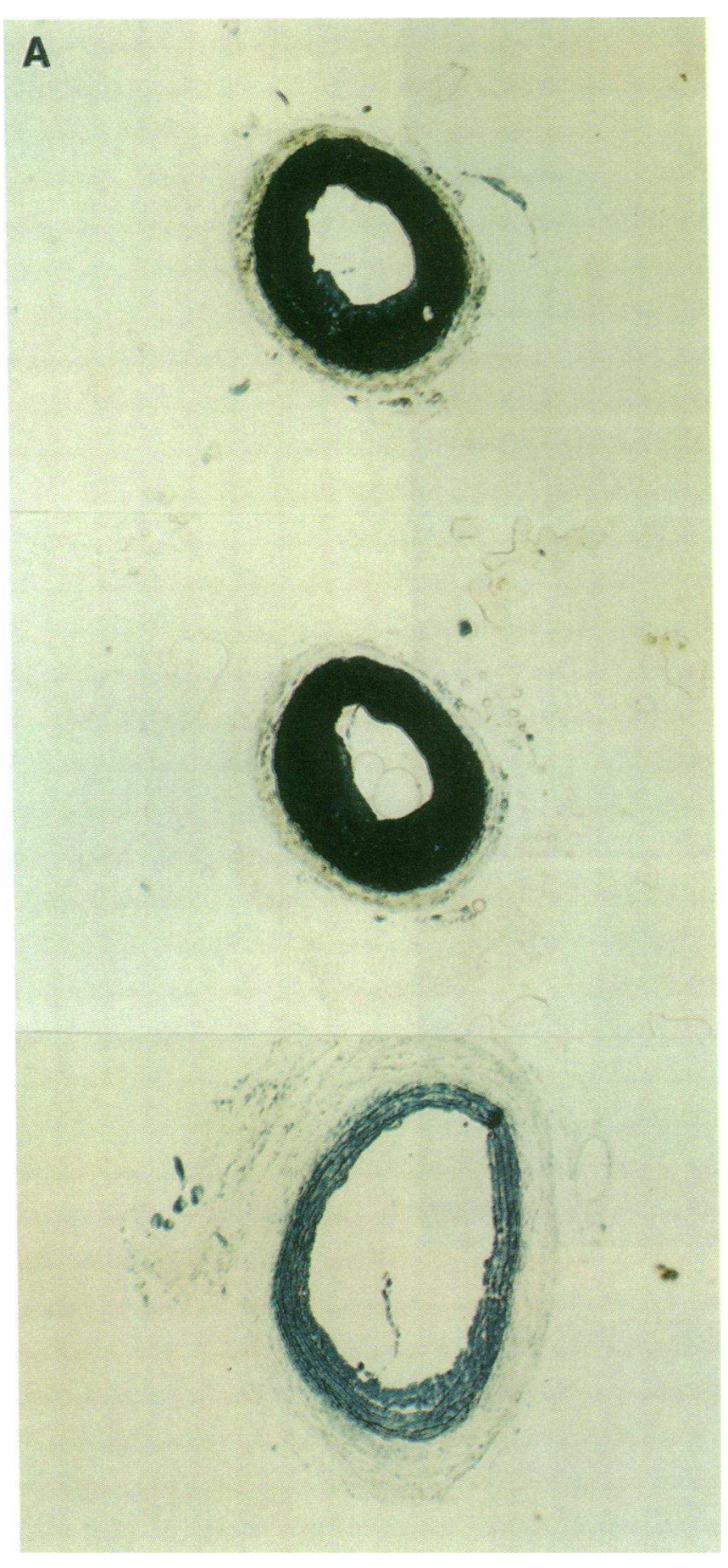

cence in the vessel wall (data not shown), demonstrating that this fluorescence was specific for FITC-labeled ODN.

\section{Discussion}

One of the important diseases potentially amendable to antisense gene therapy is restenosis after angioplasty, since the long-term effectiveness of this procedure is limited by the development of restenosis in $>40 \%$ of patients (27-29). Neointima formation after angioplasty involves a complex interaction between multiple growth factors that promote vascular smooth muscle cell proliferation and migration (1-7). Therefore, it appears unlikely that selective inhibition of a particular growth

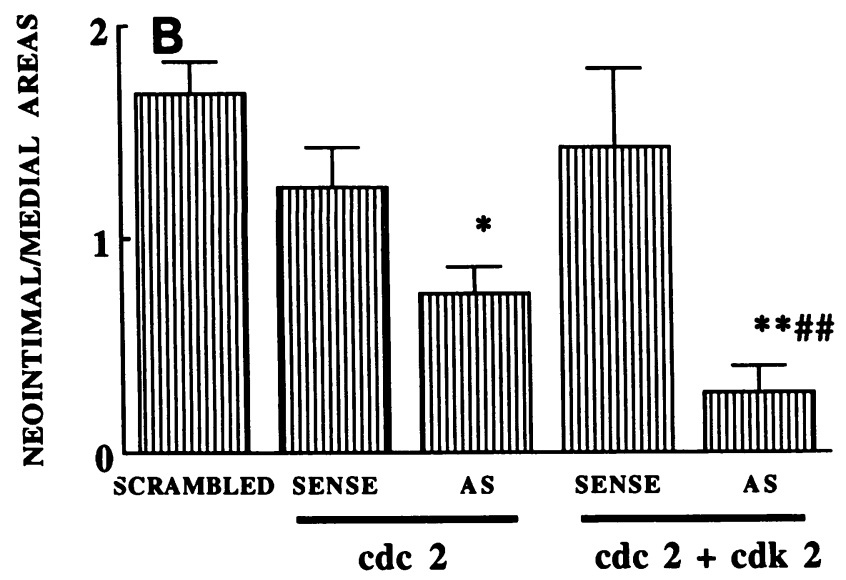

Figure 4. $(A)$ Effect of combination of antisense cdk 2 and cdc 2 kinase ODN on neointima formation. Representative cross-sections: (Top) Injured rat carotid artery without any treatment; (middle) injured carotid artery treated with HVJ-sense ODN ( $15 \mu \mathrm{M}$ each); (bottom) injured carotid artery treated with HVJ-antisense ODN ( 15 $\mu \mathrm{M}$ each $)(\times 40)$. (B) Effect of antisense cdc 2 ODN alone or combination of antisense cdc 2 and cdk 2 ODN on neointimal/medial areas ratio. ( $S C R A M B L E D$ ) Injured vessels treated with $\mathrm{HVJ}$-scrambled ODN; ( SENSE) injured vessels treated with HVJ-sense ODN; $(A S)$ injured vessels treated with $\mathrm{HVJ}$-antisense ODN. ${ }^{*} P<0.05,{ }^{* *} P$ $<0.01$ vs. sense, ${ }^{\# \#} P<0.01$ vs. AS-cdc 2 . Each group contains six to eight animals.

factor will completely prevent lesion formation. Growth factor-induced cell proliferation involves the sequential activation of intracellular proteins that promote cell cycle progression. Accordingly, we hypothesize that restenosis could be prevented by the blockade of genes regulating cell cycle progression, the final common pathway. In this study we focused on cdk 2 kinase (a serine-threonine protein kinase), which interacts to form a complex with cyclin A or other cyclins that is essential for cell cycle progression regulation (10$12,15,16)$. We postulate that cdk 2 kinase may be an ideal target for drug inhibition. Recent studies have shown that cdk 2 forms a complex with the nuclear factor, E2F, and cyclin A that transactivates other essential cell cycle regulatory genes (e.g., 

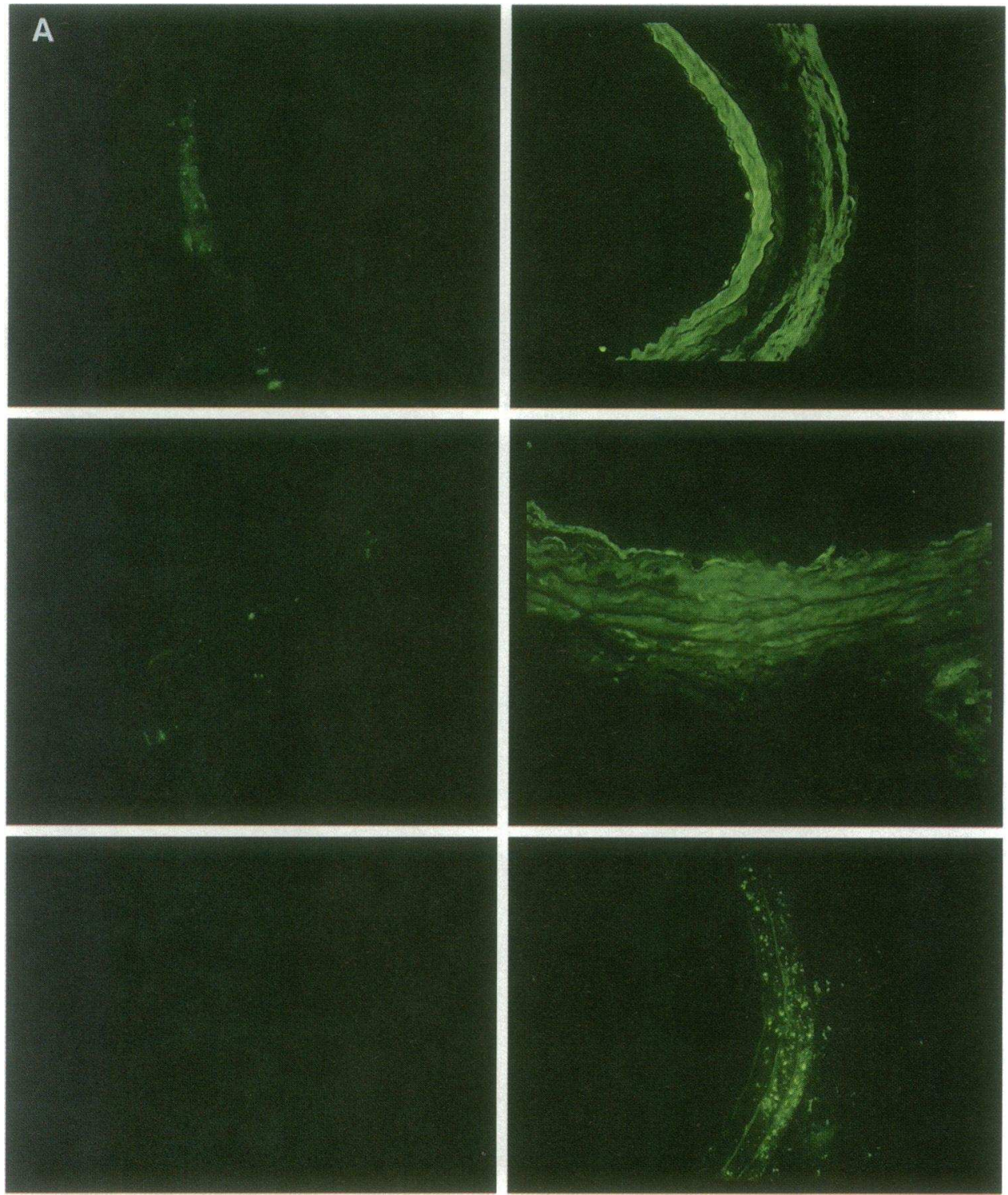

Figure 5. (A) Representative fluorescence microscopy of FITC-labeled phosphorothioate ODN in vivo using ODN-liposome complex with or without HVJ particles. (Left) ODN-liposome complex without HVJ particles; (right) HVJ transfer. The figures show the time course after transfection ( $10 \mathrm{~min}, 1 \mathrm{~d}, 4 \mathrm{~d}$ ) from top to bottom. (B) Cellular localization of FITC-labeled ODN in the vessels using $\mathrm{HVJ}$ method at 1 wk after transfection $(\times 400)$. This experiment was repeated three times. 
cdc 2 kinase, c-myc, c-myb) (10-12). We therefore tested the hypothesis that the inhibition of the expression of cdk 2 kinase would result in the inhibition of neointima formation.

Our present study demonstrates increased mRNA levels of cdk 2 kinase at $1 \mathrm{~d}$ after vascular injury in association with cell cycle progression in vivo. This increase in cdk 2 kinase mRNA expression was abolished by an intraluminal administration of antisense cdk 2 kinase ODN. A single administration of antisense cdk 2 kinase ODN resulted in a significant reduction of neointima formation at $2 \mathrm{wk}$ after transfection, whereas the medial thickness was not affected. The specificity of antisense ODN was supported by several observations: $(a)$ the decrease in cdk 2 mRNA level, but not beta-actin (Fig. 1); $(b)$ the lack of response to either sense, scrambled, or antisense thrombomodulin ODN on neointima formation (Fig. 2); (c) a 4-bp missense of the cdc 2 kinase antisense ODN had no effect on neointimal formation; $(d)$ the lack of effect of cdk 2 kinase antisense ODN administered by either direct transfer or liposome-mediated transfer without HVJ particles (Fig. 3); $(e)$ the inhibition of neointima formation was limited to the vascular segment transfected with antisense cdk 2 kinase ODN by the HVJ complex. Unfortunately, we were unable to completely inhibit neointima formation with the administration of cdk 2 antisense ODN alone. This may relate to the presence of homologues of cdk 2 kinase as well as the synergistic interaction with other cell cycle regulatory genes. Previously, we observed that cdc 2 kinase mRNA was also activated in injured arteries (13). Given the multi-complex of cell cycle regulatory genes, it was logical to examine the combination of antisense cdc 2 and cdk 2 ODN. Indeed, administration of combination of antisense cdk 2 and cdc 2 kinase ODN resulted in near complete inhibition of neointima formation. Our previous work showed a marked inhibition of neointima formation by treatment with combined antisense cdc 2 kinase and proliferating cell nuclear antigen (PCNA) ODNs (13). These results suggest that complete inhibition of cell cycle progression and neointima formation can only be achieved by the combined blockade of cell cycle regulatory genes at two or more steps. Indeed, our recent data using antisense cdc 2 kinase and cyclin $\mathrm{B}_{1}$ ODN also showed complete inhibition only when the antisense ODNs were used together (unpublished observation). The necessity to block cell cycle regulatory genes at more than one point to achieve maximum inhibitory effects may be due to the redundancy and complexity of the interactions of the cell cycle regulatory genes. During the course of our study, Simons et al. (17) reported that peri-adventitial delivery of antisense c-myb ODN via a pluronic gel inhibits neointimal formation. In addition to $c-m y b$, our study indicates that the cell cycle regulatory genes, cdc 2 kinase and cdk 2 kinase, are also involved in promoting neointimal hyperplasia after vascular injury. Simons et al. (17) used $200 \mu \mathrm{g}$ ODN per vessel, while in our study we used $20 \mu \mathrm{g}$ of ODN in liposome complex per vessel. These data suggest that the HVJ-liposome method can reduce the dosage required to achieve complete inhibition of neointima formation as compared with the pluronic gel approach.

This study provides the first documentation that the efficiency of antisense ODN to prevent neointima formation may be limited by rapid degradation within a few days of in vivo gene transfer. Our analysis of ODN uptake and kinetics within the vessel wall indicate that the method of ODN transfer is an important determinant of the therapeutic efficacy of these agents. The HVJ method appears to be more effective than other methods of ODN delivery in enhancing vascular uptake and stability of ODN. Using this intraluminal delivery system, we successfully prevented neointima formation at ODN concentrations 10 -fold lower than those reported by Simons et al. (17). We speculate that the enhanced efficiency of this system will result in fewer nonspecific toxic effects observed at high concentrations of antisense ODNs. Hence, the intraluminal delivery of antisense cdc 2 and cdk 2 ODN via the HVJ method appears to have superior therapeutic efficacy and clinical utility than previously described methods.

To understand the mechanism of the sustained effect of a single administration of ODN, we examined if ODN persisted in the vessel wall using the HVJ method. The instability of antisense ODN in vivo has been partially resolved by modifications of the ODN backbone. However, the poor cellular uptake and subsequent degradation by endocytotic-lysosomal pathways remain as major obstacles for ODN therapy $(30,31)$. In previous in vitro studies, we have shown that the HVJ-liposome-mediated transfer method for antisense ODN, which uses the fusion system mediated by $\mathrm{HVJ}$, results in intracellular ODN delivery bypassing endocytosis (18-23). Consequently, this method increases the effectiveness and prolongs the halflife of antisense ODN in vitro. Unmodified or phosphorothioate ODN delivered by liposome or passive uptake are internalized by receptor-mediated endocytosis, and become localized and degraded in endosomes (32-35). This study demonstrates that the HVJ-liposome method actually prolongs the in vivo half-life of ODN. In fact, there is evidence that the FITC-labeled ODN persists in the nucleus throughout the duration of the study. The exact mechanism(s) by which the HVJliposome method increases nuclear localization (the site of antisense action) and enhances stability cannot be addressed by this in vivo study. Nevertheless, this method is clearly efficient for sustained action of antisense ODN in vivo, and further studies to understand the mechanisms of nuclear targeting and increased stability are clearly indicated.

Here, we report that a single intraluminal administration of antisense ODN against cdk 2 kinase and / or cdc 2 kinase results in a sustained inhibition of neointima formation after balloon angioplasty in the rat carotid injury model. We believe that this study is significant for the following reasons: $(a)$ this study provides an important validation of the antisense approach, first reported in 1992 (17); (b) our study identifies newer and effective drug targets such as the cell cycle regulatory genes, cdk 2 and cdc 2 kinases, for restenosis therapy; $(c)$ we describe the application of the HVJ-liposome technology as a highly efficient method requiring only a single administration of onetenth of the antisense dose used by Simons et al. (17); $(d)$ our study uses an intraluminal approach, which is more practical for human therapy than the periadventitial approach of Simons et al. (17); and $(e)$ we performed a detailed characterization of the kinetics of the antisense ODN in the vessel wall thereby providing an explanation for the sustained effect after a single administration. Further development and application of the antisense and HVJ technology will be useful for research to characterize the biological role of the various gene products that are activated in the blood vessel after vascular injury as well as to provide potential new therapeutic agents for use in human restenosis after angioplasty.

\section{Acknowledgment}

We thank Drs. Naruya Tomita and Jitsuo Higaki for technical advise, and Melinda Hing for preparing manuscripts. 
This work was supported by National Institutes of Health grants HL-48638, HL-07708, HL-46631, HL-35252, and HL-35610, and American Heart Association Bugher Foundation Center for molecular biology. Ryuichi Morishita is the recipient of a fellowship from American Heart Association, California Affiliate. Gary H. Gibbons is a recipient of a Robert Wood Johnson Foundation Minority Faculty Development Award.

\section{References}

1. Libby, P., D. Schwartz, E. Brogi, H. Tanaka, and S. K. Clinton. 1992. A cascade model for restenosis: a special case of atherosclerosis progression. Circulation. 86:47-52.

2. Clowes, A. W., M. M. Clowes, J. Fingerle, and M. A. Reidy. 1989. Regulation of smooth muscle cell growth in injured artery. J. Cardiovasc. Pharmacol. 14:S-12-S15.

3. Fingerle, J., R. Johnson, A. W. Clowes, M. W. Majesky, and M. A. Reidy. 1989. Role of platelets in smooth muscle cell proliferation and migration after vascular injury in rat carotid artery. Proc. Natl. Acad. Sci. USA. 86:8412-8416.

4. Lindner, V., and M. A. Reidy. 1991. Proliferation of smooth muscle cells after vascular injury is inhibited by an antibody against basic fibroblast growth factor. Proc. Natl. Acad. Sci. USA. 88:3739-3743.

5. Ferns, G. A. A., E. W. Raines, K. H. Sprugel, A. S. Motani, M. A. Reidy, and R. Ross. 1991. Inhibition of neointimal smooth muscle accumulation after angioplasty by an antibody to PDGF. Science (Wash. DC). 253:1129-1132.

6. Majesky, M. W., V. Lindner, D. R. Twardzik, S. M. Schwartz, and M. A. Reidy. 1991. Production of transforming growth factor beta-1 during repair of arterial injury. J. Clin. Invest. 88:904-910.

7. Cercek, B., M. C. Fishbein, J. S. Forrester, R. H. Helfant, and J. A. Fagin. 1990. Induction of insulin-like growth factor 1 messenger RNA in rat aorta after balloon denudation. Circ. Res. 66:1755-1760.

8. Pagano, M., R. Pepperkok, F. Verde, W. Ansorge, and G. Draetta. 1992. Cyclin A is required at two points in the human cell cycle. EMBO (Eur. Mol. Biol. Organ.) J. 11:961-971.

9. Pardee, A. B. 1974. A restriction point for control of normal animal cell proliferation. Proc. Natl. Acad. Sci. USA. 71:1286-1290.

10. Weintraub, S. J., C. A. Prater, and D. C. Dean. 1992. Retinoblastoma protein switches the E2F site from positive to negative element. Nature (Lond.). 358:259-261.

11. Pagano, M., G. Draetta, and J. Durr. 1992. Association of cdk 2 kinase with the transcription factor E2F during $\mathrm{S}$ phase. Science (Wash. DC). 255:1144-1147.

12. Rosenblatt, J., Y. Gu, and D. O. Morgan. 1992. Human cyclin-dependent kinase 2 is activated during $S$ and $G 2$ phases of the cell cycle and associates with cyclin A. Proc. Natl. Acad. Sci. USA. 89:2824-2828.

13. Morishita, R., G. H. Gibbons, K. E. Ellison, M. Nakajima, L. Zhang, Y. Kaneda, T. Ogihara, and V. J. Dzau. 1993. Single intraluminal delivery of antisense cdc 2 kinase and PCNA oligonucleotides results in chronic inhibition of neointimal hyperplasia. Proc. Natl. Acad. Sci. USA. 90:8474-8478.

14. Tsai, L. H., E. Harlow, and M. Meyerson. 1991. Isolation of the human cdk 2 gene that encodes the cyclin A- and adenovirus E1A-associated p33 kinase. Nature (Lond.). 353:174-177.

15. Koff, A., M. Ohtsuki, K. Polyak, J. M. Roberts, and J. Massague. 1993. Negative regulation of $\mathrm{G} 1$ in mammalian cells: inhibition of cyclin E-dependent kinase by TGF-beta. Science (Wash. DC). 260:536-539.

16. Ewen, M. E., H. K. Sluss, C. J. Sherr, H. Matsushime, J. Kato, and D. M.
Livingston. 1993. Functional interactions of the retinoblastoma protein with mammalian D-type cyclins. Cell. 73:487-497.

17. Simons, M., E. R. Edelman, J. L. DeKeyser, R. Langer, and R. D. Rosenberg. 1992. Antisense c-myb oligonucleotides inhibit intimal arterial smooth muscle cells accumulation in vivo. Nature (Lond.). 359:67-70.

18. Tomita, N., J. Higaki, R. Morishita, K. Kato, H. Mikami, Y. Kaneda, and T. Ogihara. 1992. Direct in vivo gene introduction into rat kidney. Biochem. Biophys. Res. Commun. 186:129-134.

19. Kato, K., M. Nakanishi, Y. Kaneda, T. Uchida, and Y. Okada. 1991. Expression of hepatitis B virus surface antigen in adult rat liver. J. Biol. Chem. 266:3361-3364

20. Kaneda, Y., K. Iwai, and T. Uchida. 1989. Increased expression of DNA cointroduced with nuclear protein in adult rat liver. Science (Wash. DC). 243:375-378

21. Morishita, R., G. H. Gibbons, Y. Kaneda, T. Ogihara, and V. J. Dzau. 1993. Novel and effective gene transfer technique for study of vascular renin angiotensin system. J. Clin. Invest. 91:2580-2585.

22. Furusawa, M., T. Nishimura, M. Yamaizumi, and Y. Okada. 1974. Injection of foreign substances into single cells by cell fusion. Nature (Lond.). 249:449-450.

23. Okada, Y., I. Koseki, J. Kim, T. Hashimoto, Y. Kanno, and Y. Matsui. 1975. Modification of cell membranes with viral envelopes during fusion of cells with HVJ (Sendai virus). Exp. Cell Res. 93:368-378.

24. Furukawa, Y., H. Piwnica-Worms, T. J. Ernst, Y. Kanakura, and J. D. Griffin. 1990. cdc 2 gene expression at the $\mathrm{Gl}$ to $\mathrm{S}$ transition in human T lymphocytes. Science (Wash. DC). 250:805-808.

25. Itoh, H., M. Mukoyama, R. E. Pratt, and V. J. Dzau. 1993. Multiple autocrine growth factors modulate vascular smooth muscle cells growth response to angiotensin II. J. Clin. Invest. 91:2268-2274.

26. Kittelberger, R., P. F. Davis, and W. E. Stehbens. 1989. An improved immunofluorescence technique for the histological examination of blood vessel tissue. Acta Histochem. 86:137-142.

27. McBride, W., R. A. Lange, and D. A. Hillis. 1988. Restenosis after successful coronary angioplasty: Pathology and prevention. N. Engl. J. Med. 318:17341737.

28. Tcheng, J. E., D. J. Frid, D. F. Fortin, C. L. Nelson, R. K. Stack, R. H. Peter, R. S. Stack, and R. M. Califf. 1991. Anatomic propensity for restenosis following coronary angioplasty. J. Am. Coll. Cardiol. 17:345a. (Abstr.)

29. Califf, R. M., D. F. Fortin, D. J. Frid, W. R. Harlan, E. M. Ohman, J. R. Bengtson, C. L. Nelson, J. E. Tcheng, D. B. Mark, and R. S. Stack. 1991. Restenosis after coronary angioplasty: an overview. J. Am. Coll. Cardiol. 17:2-13.

30. Marcus-Sekura, C. J. 1988. Techniques for using antisense oligodeoxynucleotides to study gene expression. Anal. Biochem. 172:289-295.

31. Stein, C. A., and J. S. Cohen. 1988. Oligodeoxynucleotides as inhibitors of gene expression: a review. Cancer Res. 48:2659-2668.

32. Spiller, D. G., and D. M. Tidd. 1992. The uptake kinetics of chimeric oligodeoxynucleotides analogues in human leukemia MOLT -4 cells. Anti-Cancer Drug Des. 7:115-129.

33. Bennett, C. F., M. Y. Chiang, H. Chan, J. E. E. Shoemaker, and C. K. Mirabelli. 1992. Cationic lipids enhance cellular uptake and activity of phosphorothioate antisense oligonucleotides. Mol. Pharmacol. 41:1023-1033.

34. Leonetti, J. P., N. Mechti, G. Degols, C. Gagnor, and B. Lebleu. 1991. Intracellular distribution of microinjected antisense oligonucleotides. Proc. Natl. Acad. Sci. USA. 88:2702-2706.

35. Akhtar, S., and R. L. Juliano. 1992. Cellular uptake and intracellular fate of antisense oligonucleotides. Trends Cell Biol. 2:139-144. 